RESEARCH NOTE

\section{Occurrence of Cystacanths of Centrorhynchus sp. (Acanthocephala: Centrorhynchidae) in Toads of the Genus Eupsophus in Chile}

\author{
Patricio Torres ${ }^{+}$, Sonia Puga \\ Instituto de Parasitología, Universidad Austral de \\ Chile, Casilla 567, Valdivia, Chile
}

Key words: Centrorhynchus - cystacanths Eupsophus - toads - Chile

In Chile, there are about 43 anuran species. However, research on their helminth fauna is limited to nine parasite species: the trematodes Gorgoderina chilensis Dioni, 1947, Gorgoderina valdiviensis Puga, 1979 and Rudolphitrema chilensis Puga, 1986; the cestodes Ophiotaenia noei Wolfhügel, 1950 and Baerietta chilensis Puga and Franjola, 1983; the nematodes Aplectana chilensis Lent and Freitas, 1948 Cosmocerca chilensis Lent and Freitas, 1948 and Oswaldocruzia neghmei Puga, 1981; and the acanthocephalan Acanthocephalus caspanensis Fernández and Ibarra, 1989. These helminths were reported from nine host species (S Puga 1994 Bol Chil Parasitol 49: 81-84).

This note presents the occurrence of cystacanths of acanthocephalans of the genus Centrorhynchus in toads of the genus Eupsophus (Leptodactylidae) for the first time.

The genus Eupsophus includes endemic species that live in leaf beds of the temperate forests of South America (R Formas 1979 Univ Kansas Mus Nat Hist Monograph 7: 341-369).

This work was supported by grant S-94-34 (Dirección de Investigación y Desarrollo, Universidad Austral de Chile)

${ }^{+}$Corresponding author. Fax: +56-63-214475

Received 26 January 1996

Accepted 3 April 1996
Necropsies of 27 adult E. calcaratus from Yaldad ( $\left.43^{\circ} 5^{\prime} \mathrm{S}, 73^{\circ} 43^{\prime} \mathrm{W}\right)$, on the island of Chiloé, and 10 E. roseus from Isla Teja $\left(39^{\circ} 48^{\prime} \mathrm{S}\right.$, $73^{\circ} 15^{\prime} \mathrm{W}$ ), in the city of Valdivia, were carried out between July 1994 and January 1995.

Adult male and female toads were collected by hand. Live acanthocephalans were placed in water at $4{ }^{\circ} \mathrm{C}$ for about $10 \mathrm{hr}$, fixed in alcohol-formalinacetic acid, preserved in $70 \%$ ethanol, and cleared in lactophenol. Liver samples infected with acanthocephalans were fixed in buffered neutral $10 \%$ formalin. Paraffin-embedded sections were cut and stained with hematoxylin and eosin. Drawings were made with the aid of a camera lucida.

Morphological characteristics (Figs 1-2) and measurements (in $\mu \mathrm{m}$ unless otherwise indicated) of three males were as follows: trunk 3.2-4.4 (3.9) $\mathrm{mm}$ long by 663-881 (795) at the greatest width. Proboscis 1.0-1.2 (1.1) $\mathrm{mm}$ long by 491-554 (517) at the greatest width, with 30-32 rows of 18-20 hooks each. Proboscis receptacle 1.1-1.2 (1.2) mm long. Lemnisci extending beyond the end of the proboscis receptacle to the level of the testes. Testes in ligament sac 94-117 (103) long by 62-78 (72) at the greatest width in two specimens, in other one 460-480 long by $420-460$ wide.

Cystacanths of Centrorhynchus sp. were found in liver and/or peritoneum of $3(11.1 \%) E$. calcaratus with one to three specimens per host; while in only one specimen (10\%) of E. roseus 2 cystacanths were found in the liver.

Specimens found in the hepatic tissue were surrounded by a fibrotic capsule (Fig. 3) as has been reported for other Centrorhynchus spp. in frogs (F Cox 1971 J Biol Educ 5: 35-51, O Amin 1982 Classification of Living Organisms, p. 933940. In ED Parker, New York).

Centrorhynchus sp. is the first helminth reported for E. calcaratus. O. neghmei and $R$. chilensis have been reported previously for $E$. roseus (Puga loc. cit.).

The genus Centrorhynchus includes about 75 species (O Amin 1985 Biology of Acanthocephala, p. 27-72. In DWT Crompton, BB Nickol, Cambridge) the definitive hosts of which are diurnal or nocturnal rapacious birds (Falconiforms or Strigiforms). Their intermediate hosts are terrestrial isopods or insects, Orthoptera or Coleoptera, and their various paratenic hosts, amphibians, reptiles, and mammals, play a fundamental role in their transmission to birds (J Buron \& Y Golvan 1986 Ann Parasitol Hum Comp 5: 581-592).

E. calcaratus and E. roseus perhaps serve as paratenic hosts for Centrorhynchus sp. for which the definitive and intermediate hosts are unknown. 
718 Centrorhynchus sp. in Eupsophus spp. in Chile • P Torres, S Puga

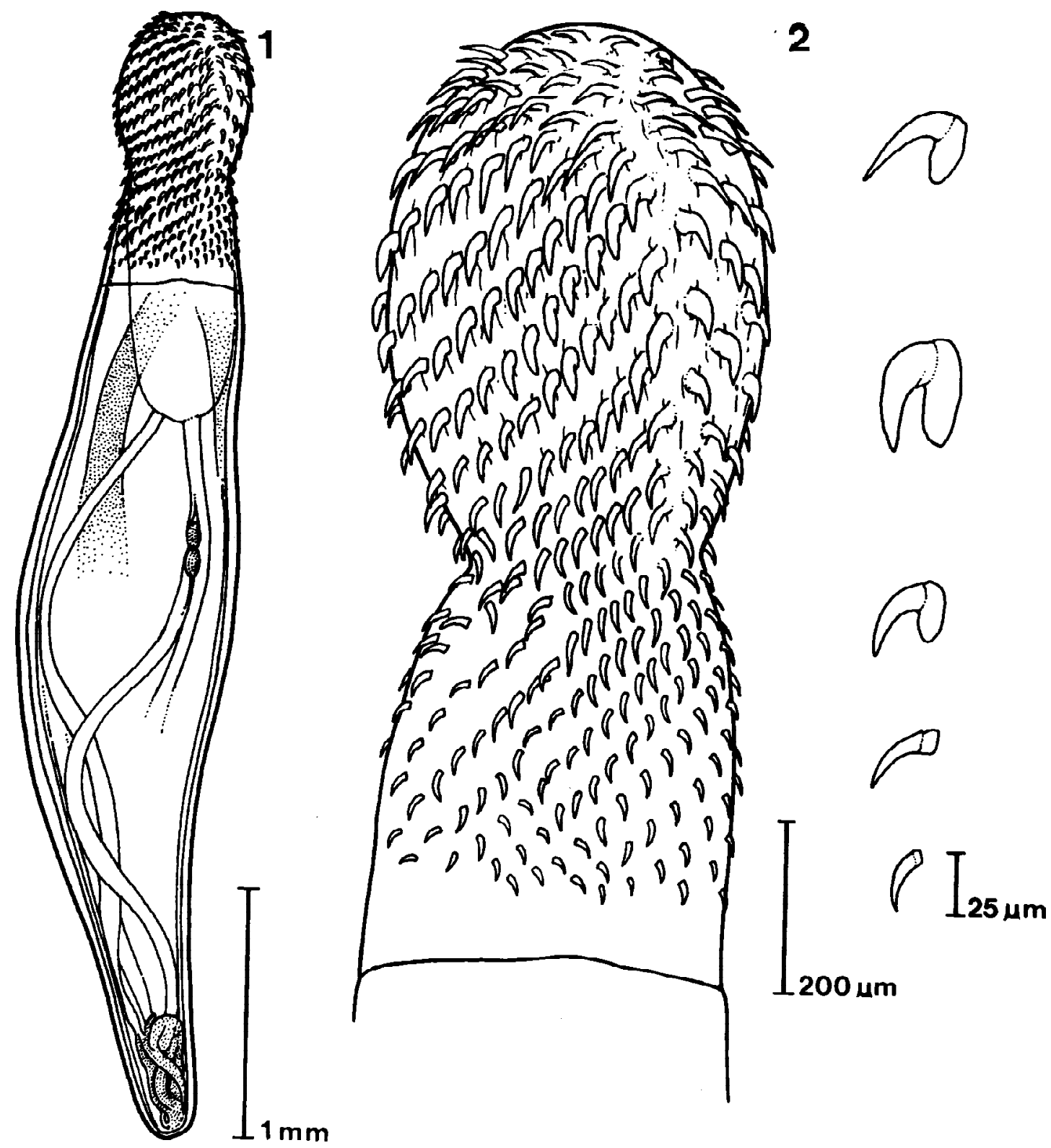

Cystacanth of Centrorhynchus sp. in toads of genus Eupsophus from Chile. Fig. 1: general view. Fig. 2: proboscis with details of hooks. 


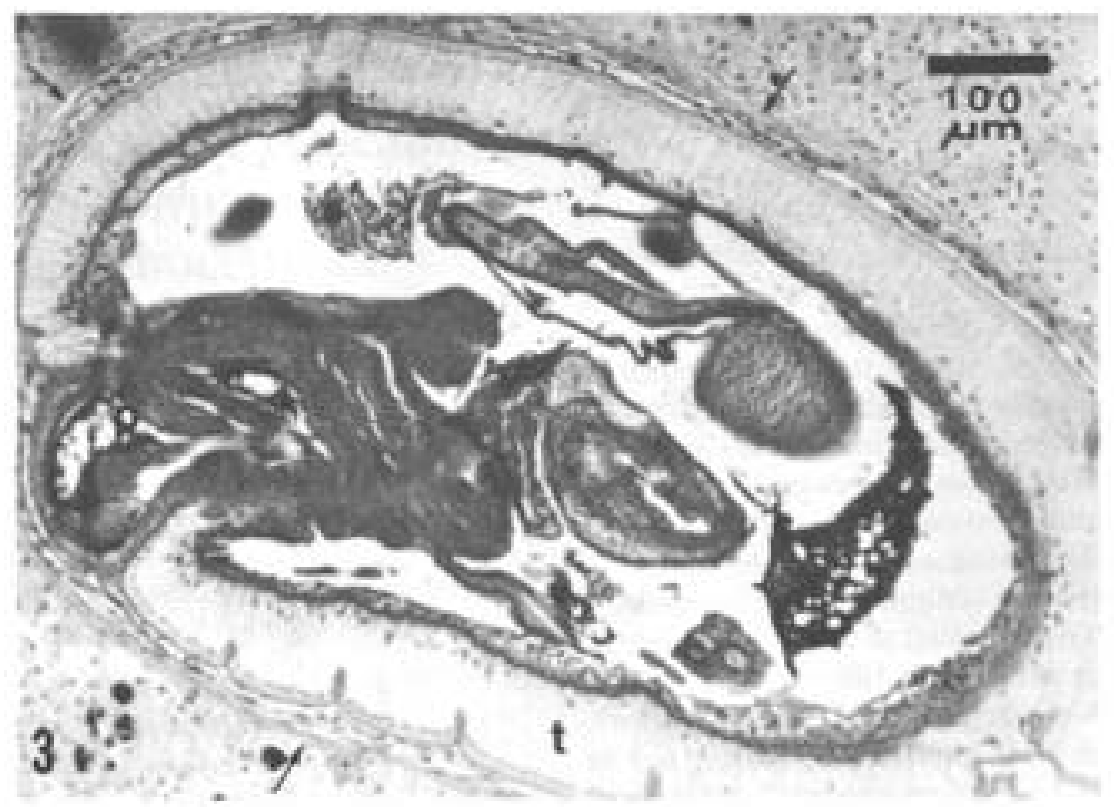

Hepatic histological section with cystacanth of Centrorhynchus sp. in toads of genus Eupsophus from Chile. Fig. 3: cystacanth, surrounded by capsule (arrow) of the host, tegument (t), region of proboscis (p).

The diet of $\quad \mathrm{s}$ (Formas loc. cit that these hosts would be infected through the consumption of insects.

collection of the Institute of Parasitology,
Universidad Austral de Chile, Valdivia, Chile (IPUAT No. 0247-0248).

Acknowledgements: to Dr Ramón Formas (Instituto de Zoología, Universidad Austral de Chile) for the identification of toads. 
